\title{
Study of Percutaneous Lumbar Decompression and Treatment Algorithm for Patients Suffering from Neurogenic Claudication
}

Timothy R. Deer, MD, Christopher K. Kim, MD, Richard G. Bowman II, MD, Matthew T. Ranson, MD, and Brian Scott Yee, DO

From: The Center for Pain Relief, Charleston, WV

Address Correspondence: Timothy R. Deer, MD The Center for Pain Relief, Inc.

400 Court Street, Suite 100 Charleston, WV 25301 E-mail: Doctdeer@aol.com

Disclaimer: There was no external funding in the preparation of this manuscript. Conflict of interest: Dr. Deer is a consultant for Vertos maker of MILD.

Manuscript received: 05/29/2012

Revised manuscript received: o6/26/2012

Accepted for publication: 07/26/2012

Free full manuscript: www.painphysicianjournal. com
Background: Symptomatic lumbar spinal stenosis (LSS) patients often suffer from multiple etiologies, and patient symptoms must be differentiated and identified as either neurogenic claudication, radicular pain, or both. The most common symptom associated with LSS is neurogenic claudication, which has been reported to occur in $91 \%$ to $100 \%$ of the LSS patient population. Neurogenic claudication symptoms are described as pain radiating to the lower extremities that begins and worsens as the patient ambulates. Neurogenic claudication symptoms worsen over time and can eventually result in significant life-altering functional limitations. Symptomatic LSS patients may also suffer from radicular pain, which is a persistent pain transmitted through neural pathways, and is associated with inflammation of the exiting nerve root.

Objective: To assess patient safety, pain reduction, and functional status of patients treated with percutaneous lumbar decompression.

Study Design: Single-center, prospective clinical study of 46 consecutive patients with neurogenic claudication symptoms related to lumbar spinal stenosis.

Setting: US interventional pain management practice.

Methods: From March 2010 to January 2011, 46 LSS patients suffering from neurogenic claudication underwent mild percutaneous lumbar decompression. Of these, 12-week, 6-month and one-year followup was available for 35 patients.

Outcome Assessment: Visual Analog Scale (VAS), Oswestry Disability Index (ODI), and Zurich Claudication Questionnaire (ZCQ). Outcomes were assessed at baseline, 12-week, 6-month and one-year follow-up.

Results: One-year follow-up patients in this study experienced statistically and clinically significant improvement in physical function, as well as reduction of pain intensity. The initial improvement in these patients, which was significant, was sustained through one year, with no significant differences among the interim follow-up visit periods. These results demonstrate early improvement following treatment with a high degree of durability over time. There were no serious device or procedure-related complications reported in this study.

Limitations: Single-center study with no control group.

Conclusions: In this study, the mild procedure was shown to be safe. In addition, patients experienced significant improvement in mobility and reduction of pain one year after the procedure. One-year outcomes were not significantly different from interim results, indicating that the significant improvement following treatment, occurring as early as 12 weeks, was maintained through one year. This high degree of consistency over time indicates the durability of percutaneous lumbar decompression in the treatment of neurogenic claudication in symptomatic LSS.

Key words: Spine, lumbar, lumbar spinal stenosis, neurogenic claudication, decompression, ligamentum flavum, mild, percutaneous.

Pain Physician 2012; 15:451-460 
n 1976, Arnoldi and colleagues (1) defined lumbar spinal stenosis (LSS) as any type of narrowing of the spinal canal, nerve root canals, or intervertebral foramina. This narrowing is caused by degenerative changes in the lumbar spine, including hypertrophy of the ligamentum flavum and facet joints, osteophyte formation, and bulging or herniated discs (2-6). These changes lead to compression of neural elements and painful symptoms of LSS (6). The hallmark symptom of LSS is neurogenic claudication (NC), which is characterized as pain that worsens with axial loading and lessens with forward flexion. LSS patients may also suffer from radicular pain, described as radiating pain in a dermatomal pattern that is present irrespective of activity (7).

LSS is a common clinical condition that generally affects men and women in their fifth to seventh decades of life. Initially, symptomatic LSS patients are treated with conservative management, which can include nonsteroidal anti-inflammatory drugs, analgesic medications, physical therapy, and epidural steroid injections (8-17). While epidural steroid injections may provide some modest relief of inflammation related to radicular pain, they may not be effective in treating painful NC which is not caused by inflammation, but instead results from compression or ischemia of neural structures (10). In the past, once conservative therapies have failed, decompression surgery has been the next option for these patients. Surgical management of LSS has traditionally involved wide laminectomy or "unroofing" of the spinal canal. However, more recently, less invasive surgical techniques have been developed, which are intended to shorten recovery times, decrease complication rates, and reduce tissue trauma and iatrogenic instability (18-28).

The goal of this study was to evaluate the safety and outcome of symptomatic LSS patients treated with mild percutaneous lumbar decompression (Vertos Medical, Aliso Viejo, CA). Percutaneous lumbar decompression treats LSS by removing small but adequate portions of lamina and ligamentum flavum, thereby restoring space in the spinal canal. The mild procedure is conducted using a fluoroscopically guided, centralized dorsal approach which significantly enhances the safety of the procedure by virtually eliminating the possibility of certain serious complications including dural tear, blood loss requiring transfusion, or lateral nerve damage. The procedure is performed through a 6-gauge port under fluoroscopic guidance, with minimal tissue disruption. This report presents comprehensive safety data and patient reported outcomes at 12 weeks, 6 months, and one year following treatment with mild percutaneous lumbar decompression.

\section{Methods}

\section{Study Design}

This is a prospective, single-center study of LSS patients presenting with symptoms of NC and treated with mild percutaneous lumbar decompression. Fortysix patients were enrolled in this study from March 2010 toJanuary 2011 at The Center for Pain Relief in Charleston, West Virginia. Informed consent was obtained from all patients, and the study protocol was approved by an institutional review board and was registered with the US Clinical Trial Registry (NCT01076244).

\section{Inclusion and Exclusion Criteria}

Study inclusion criteria required enrollment of adult LSS patients suffering from NC primarily caused by ligamentum flavum (LF) hypertrophy, although the presence of other less predominant contributing factors was not exclusionary. Preoperative magnetic resonance imaging (MRI) or computed tomography (CT) provided radiologic evidence of hypertrophic LF > 2.5 $\mathrm{mm}$, as well as a clearly reduced central canal crosssectional area. Patients were required to walk a minimum of 10 feet unaided before being limited by pain, and must have failed prior conservative therapy. Patients were excluded if they suffered from severe back or leg pain from causes other than LSS, had experienced a recent spinal fracture, or had undergone prior surgery at the intended treatment level. Patients were also excluded if disc protrusion or facet hypertrophy were deemed severe enough to potentially confound study outcomes. Further, patients who had used nonsteroidal anti-inflammatory drugs within 5 days or had been administered epidural steroid injections within 3 weeks prior to the study procedure were excluded. Patients with bleeding disorders and current users of anticoagulants were also excluded.

\section{Procedure}

The mild procedure is performed percutaneously using disposable instruments provided in one kit that are specifically designed for the procedure. The procedure is typically performed in an outpatient setting using monitored anesthesia care. This procedure has been previously described in detail (18-25), therefore a limited review follows. 
With the patient prone and abdominal boost positioned, the skin is marked to indicate target treatment level(s). An epidurogram is performed at the level and side to be decompressed. A small incision is made approximately one-and-a-half levels below the treatment level to accommodate introduction of the 6-gauge portal/trocar assembly. Use of contralateral oblique fluoroscopy provides optimal visualization. The trocar is removed and the portal is stabilized using a portal stabilizer. In addition, a depth guide is attached to assist the user in controlling instrument depth. Using a bone rongeur, small bits of laminar bone are removed to gain access to the ligamentum flavum, which is subsequently debulked using the tissue sculpter. Once it has been determined that resection is sufficient and contrast medium flow indicates acceptable restoration of space in the canal, the instruments are removed and a sterile strip applied to close the wound.

\section{Outcomes Assessments}

The Visual Analog Scale (VAS), Oswestry Disability Index (ODI), and Zurich Claudication Questionnaire (ZCQ) patient assessment scales were used to evaluate percutaneous decompression outcomes in this study. These assessments are reported for baseline and at 12-weeks, 6-months, and one-year follow-up.

The VAS provides a numerical measurement of back and leg pain intensity on a ten-point continuum, with one denoting no pain and ten indicating the worst pain possible. The ODI provides a measurement of functional disability resulting from chronic back pain. ODI scores range from zero to 100 , with higher scores signifying greater disability. The ZCQ is a validated patient-reported outcomes tool ZCQ consists of Symptom Severity and Physical Function domains that are recorded at baseline and at each follow-up interval. The Symptom Severity domain has been subdivided into 2 subsets-the Pain domain and the Neuro-ischemic domain. In addition, ZCQ also contains a Patient Satisfaction Domain that is completed only at follow-up. For each ZCQ domain, higher scores indicate worse patient condition. As a validated patient outcome tool specific to LSS, ZCQ provides information specifically related to spinal disability (29-31).

Safety was monitored throughout the study, and all device or procedure-related serious adverse events were recorded. Serious adverse events were defined as significant blood loss requiring blood transfusion, nerve injury, epidural bleeding or hematoma, dural puncture or tear, or any other device or procedure-related signifi- cant complications.

\section{Statistical Analysis}

All patients treated with the mild procedure after providing informed consent serve as the comprehensive safety population, and their functional and patient-reported outcomes are analyzed and presented by postoperative follow-up period. Patient characteristics are reported using descriptive statistics. Means, standard deviations, and confidence intervals are reported for continuous variables. Where appropriate, the $95 \%$ 2-sided exact confidence intervals (upper and lower) were computed.

Primary efficacy endpoints are the absolute change in VAS, ODI and ZCQ between the preoperative value and one-year. For the VAS and ODI, an Analysis of Variance (ANOVA) with Repeated Measures and post hoc Tukey HSD Test were employed to assess the change over time from baseline, through 12 weeks, 6 months and one year (alpha level $=0.05$ ). For $Z C Q$, a 2-sided ttest for correlated values was used to assess the change over time from baseline to one year (alpha $=0.05$ ). Missing value imputations were performed using the Last-Observation-Carried-Forward method. Both imputed and nonimputed samples were analyzed.

\section{Results}

Forty-six patients were treated with mild percutaneous lumbar decompression at The Center for Pain Relief in Charleston, West Virginia, from March 2010 to January 2011. This patient series included 17 men $(37 \%)$ and 29 women (63\%), with a mean age of 66.1 years (range 46 to 80 ). Thirty-four patients (74\%) had been under medical management for over 6 months; 3 patients (7\%) for 3 to 6 months; and 9 patients (20\%) had been under medical management for less than 3 months.

In addition to ligamentum flavum hypertrophy, which was a requirement for study inclusion, a number of other patient etiologies that can lead to symptoms of LSS were reported. While $100 \%$ of patients experienced ligament flavum hypertrophy, 43 patients (93\%) suffered from facet hypertrophy, and 41 patients (89\%) suffered from a bulging disc.

Study patients underwent a total of 112 procedures, including decompression of 44 levels bilaterally and 24 levels unilaterally. One-level decompression was performed on 24 patients (52\%); 2-level decompression on 22 patients (48\%). The majority of decompressions $(89 \%)$ were performed at L3-L4 or L4-L5. Figure 1 
presents treatment levels for these procedures.

Mean treatment time was 41 minutes from patient entry to departure from the operating room. Fluoroscopy time ranged from 38 to 279 seconds, with a mean of 104 seconds and median of 98 seconds. All patients underwent mild percutaneous lumbar decompression with monitored anesthesia care/light sedation, and all patients were discharged on the same day as the procedure. There were no major device or procedure-related complications reported in this study.

VAS and ODI outcome data were available at all follow-up periods for 35 of the 46 patients. For 8 of 11 patients with missing data at one or more followup periods, supplementary analyses imputed missing VAS or ODI post-baseline data with last-observationcarried-forward (LOCF). All of these 8 patients were missing data for only one follow-up visit: one was missing 12-week follow-up, one was missing six-month follow-up, and 6 patients were missing one-year follow-up. These analyses are presented below. Of the 3 patients that are not included in these analyses, one patient withdrew consent, and 2 patients underwent back surgery and were discontinued from the study. The patient who withdrew consent had reported a 4 point improvement in VAS, and a 20 point improvement in ODI following the mild procedure, but opted to not continue with study assessments. Both patients who underwent back surgery presented with high levels of baseline pain and functional disability. One patient had a history of ligamentum flavum hypertrophy, disc bulge, facet hypertrophy, foraminal stenosis, Grade I anterolisthesis of L4-L5, and disc osteophyte formation, and had been under LSS medical management for more than 6 months. At 171 days post-mild, this patient underwent lumbar fusion at L3-L4 and L4L5. The medical history of the other patient included ligamentum flavum hypertrophy, disc bulge, facet hypertrophy, foraminal narrowing, osteophytes, and severe scoliosis, with LSS medical management duration greater than 6 months. On the 69th day post-mild, an L5-S1 laminectomy was performed. These 2 patients experienced improvement in both pain intensity and physical function following percutaneous lumbar decompression and, although improved at the time of discontinuation, given their severe baseline condition, required more invasive treatment.

In the 35-patient cohort, pain intensity as measured by VAS improved significantly from a mean of 6.9

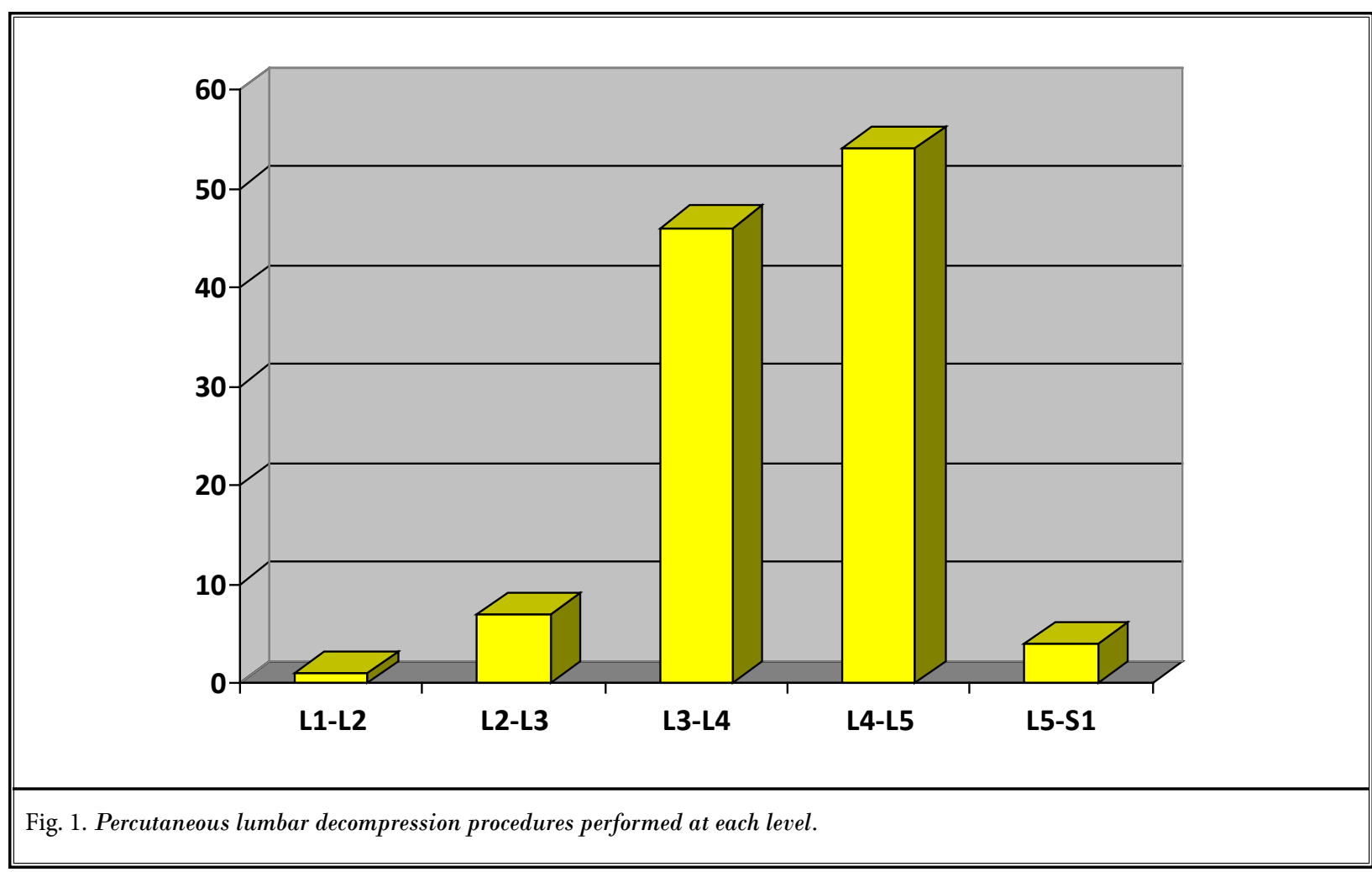


(95\% confidence interval $[\mathrm{Cl}] \pm 0.6)$ at baseline to an average of $4.0(95 \% \mathrm{Cl} \pm 1.0)$ at one-year follow-up, a 2.9 point improvement. The interim mean VAS values were $4.2(95 \% \mathrm{Cl} \pm 1.0)$ at 12-week follow-up and 4.4 $(95 \% \mathrm{Cl} \pm 1.0)$ at 6-month follow-up, demonstrating improvements of 2.7 and 2.5 points, respectively (Fig. 2). Improvement from baseline through one year followup was statistically significant (ANOVA for repeated measures, $P<0.0001$ ). Interestingly, the Tukey HSD Test found the improvement at each postbaseline period (12 weeks, 6 months, and one year) to be significantly different from baseline $(P<0.01)$; however, no significant difference was seen between the postbaseline periods. These results demonstrated the improvement following treatment occurred as early as 12 weeks and was maintained through one-year-indicating a high degree of consistency over time.

When the LOCF was imputed for the 8 patients with missing VAS data postbaseline, 5 of whom showed no improvement following treatment, the overall improvement described above was still observed (ANOVA for repeated measures, $P<0.0001$ ). Similarly, the Tukey HSD Test found the same VAS improvement at 12-week, 6-month, and one-year follow-ups relative to baseline as described above.

Also, patients experienced a statistically significant mobility improvement from baseline to one-year follow-up. Their ODI improved from a mean of 49.4 (95\% $\mathrm{Cl} \pm 2.5)$ at baseline to $32.0(95 \% \mathrm{Cl} \pm 5.8)$ at one-year follow-up, a 17.4 point improvement. The interim mean ODI values were $35.1(95 \% \mathrm{Cl} \pm 5.6)$ at 12 -week followup and $35.0(95 \% \mathrm{Cl} \pm 5.5)$ at 6-month follow-up, an improvement of 14.3 and 14.4 points, respectively (Fig. 3). Improvement from baseline through one-year followup was statistically significant (ANOVA for repeated measures, $P<0.0001)$. Similar to VAS, the Tukey HSD Test found the improvement at each postbaseline period (12 weeks, 6 months, and one year) to be significantly different from baseline $(P<0.01)$; however, no significant difference was seen between the postbaseline periods. These results demonstrated the improvement following treatment occurred as early as 12 weeks and was maintained through one year-indicating a high degree of consistency over time.

When the LOCF was imputed for the 8 patients with missing ODI data postbaseline, the overall im-

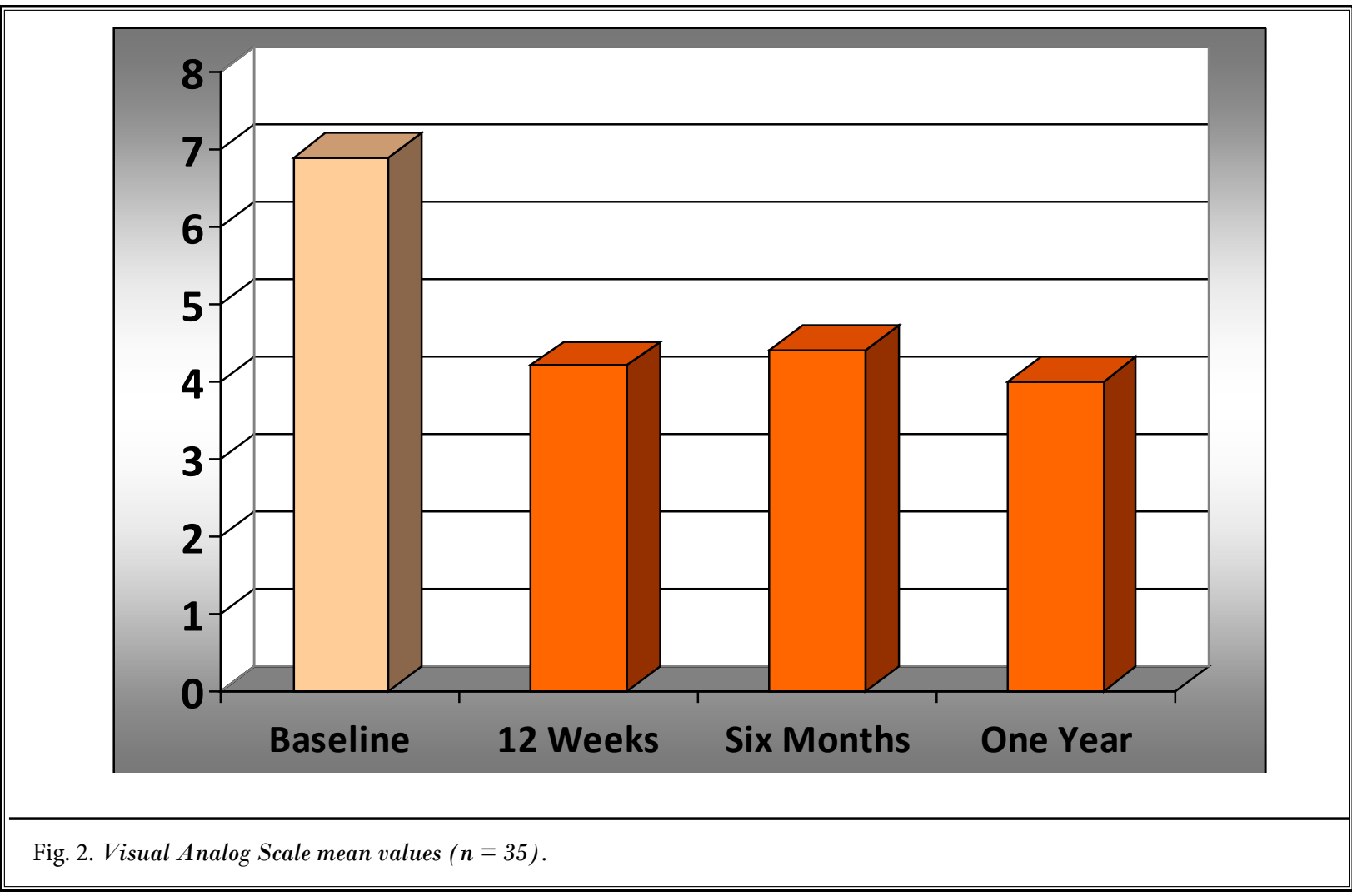




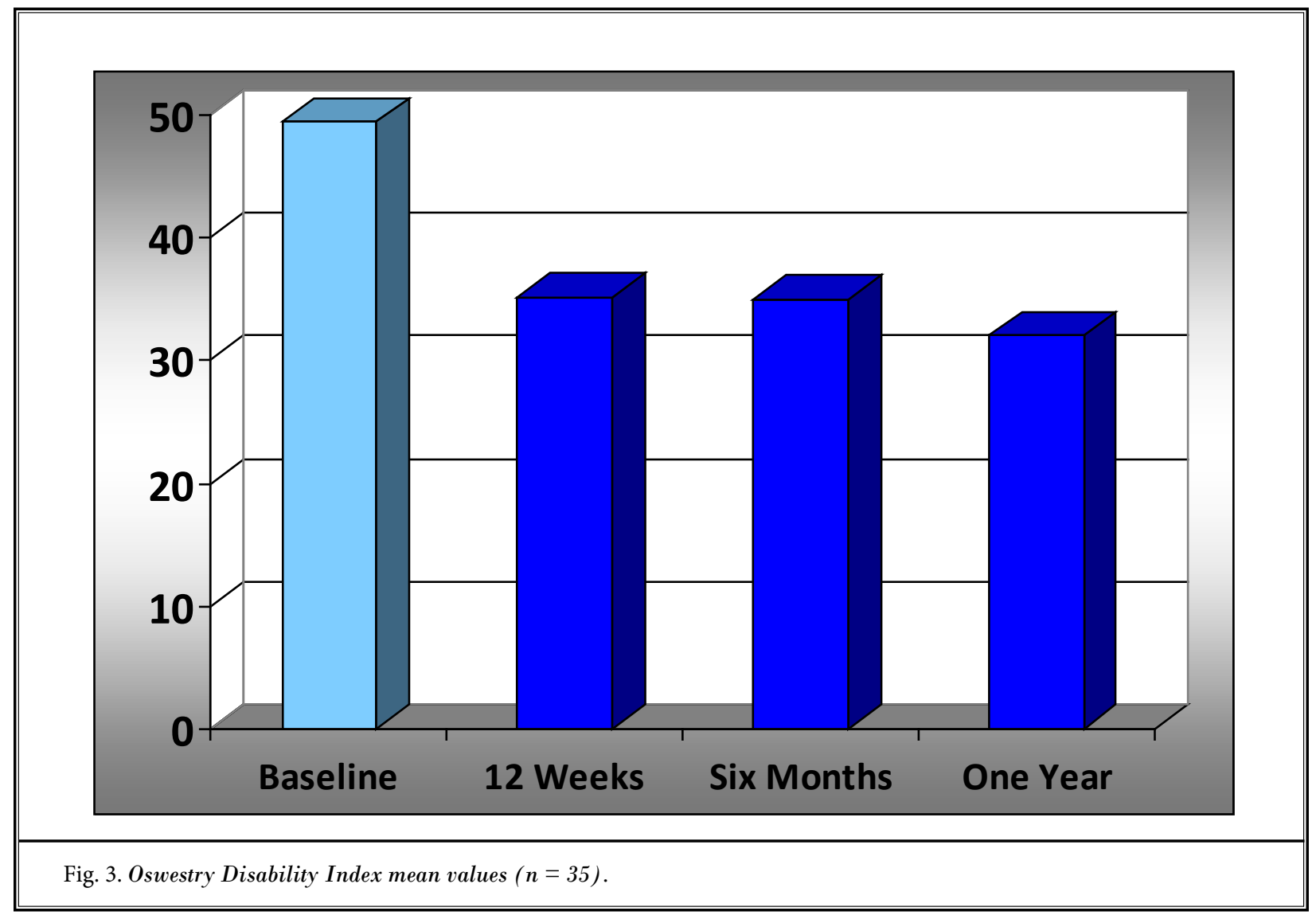

provement described above was still observed (ANOVA for repeated measures, $P<0.0001$ ). Similarly, the Tukey HSD Test found the same ODI improvement at 12 weeks, 6 months, and one year follow-up relative to baseline as described above.

At one-year follow-up, 34 patients of the 35-patient cohort responded to the ZCQ. Statistically significant improvements were achieved in all ZCQ domains, including Symptom Severity, both Symptom Severity sub-domains (Pain and Neuro-Ischemic) and Physical Function (paired t-test; $P<0.0001$ ). Overall Symptom Severity improved from a mean of 3.5 at baseline to 2.3 at one-year follow-up, a decrease of 1.2 points. The Pain Sub-Domain of Symptom Severity improved from a baseline average of 3.9 to 2.7 at one-year follow-up, a decrease of 1.2 points. The Neuro-Ischemic Sub-Domain of Symptom Severity decreased from 3.0 to 1.9 over the same period, demonstrating an improvement of 1.1 points. Physical Function improved from an average of 2.7 at baseline to 1.9 at one-year follow-up, a decrease of 0.8 points. These values, together with interim 12week and 6-month scores for each of the ZCQ Domains are presented in Fig. 4.

The average score on the ZCQ Satisfaction Scale at one year was 1.86, indicating that patients were satisfied with their overall outcomes after percutaneous lumbar decompression. On the 4-point patient Satisfaction Scale, a rating of "1" indicates that the patient is Very Satisfied and a rating of " 2 " indicates that the patient is Satisfied. With a $95 \%$ Confidence Interval of $1.86 \pm 0.24$, lower and upper limits are 1.61 and 2.10, respectively. Further, $88 \%$ of patients reported that they were satisfied with the outcome of mild percutaneous lumbar decompression.

\section{Discussion}

Proper diagnosis of LSS requires both clinical and radiologic patient assessments. However, it should be noted that the association between the degree of spinal canal narrowing and clinical symptoms is uncertain. In some cases, radiologic findings have been reported to be divergent from clinical symptoms, both in demonstrating false positive central canal narrowing in patients without symptoms, as well as indicating false 


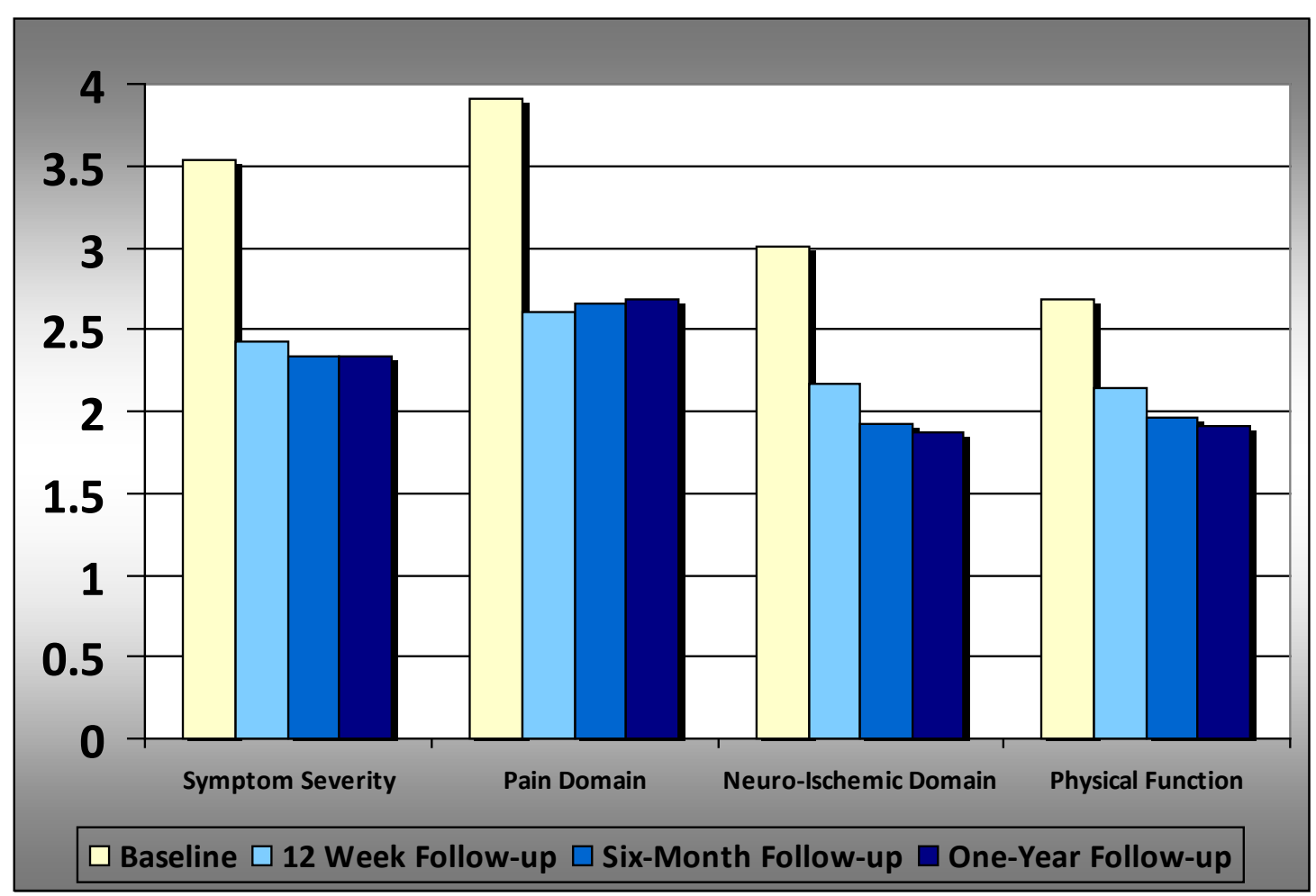

Fig. 4. Zurich Claudication Questionnaire mean values $(\boldsymbol{n}=34)$.

negative normal canal appearance in patients with symptoms (7,32-35). While baseline MRI or CT providing radiologic evidence of clearly reduced central canal cross sectional area was required for inclusion in this study, these findings are considered to be only ancillary to the more crucial reports of pain intensity and functional disability experienced by these patients.

The most common symptom associated with LSS is NC which has been reported to occur in $91 \%$ to $100 \%$ of the LSS patient population (32,34-39). NC was first described by Verbiest in 1954 (40) as structural narrowing of the vertebral canal that compresses the cauda equina. Narrowing of the central vertebral canal is thought to cause venous hypertension resulting in nerve root ischemia, and NC symptoms (41-43). NC symptoms are described as pain radiating to the lower extremities that begins and worsens as the patient ambulates. The pain often resolves as the patient bends forward or sits down (44-45). NC symptoms worsen over time and can eventually result in significant life-altering functional limitations.
Conversely, radicular pain is persistent pain transmitted through neural pathways. Severe foraminal and/ or sub-articular stenosis can compromise the lateral recess leading to radiculopathy--described as inflammation of the exiting nerve root. Most often this presents as "sciatica," and is described as persistent pain in the lower back, buttocks and legs. This pain can be unilateral or bilateral, and range from dull and aching to dysesthetic or sharp (6). Radicular pain is diagnosed through identification of a dermatomal pain pattern. Since radicular pain is associated with inflammation, some success has been reported with the administration of repeated epidural steroid injections $(9,46,47)$.

Symptomatic LSS patients often suffer from multiple etiologies, and patient symptoms must be differentiated and identified as either NC, radicular pain, or both. Importantly, when evaluating proper treatment of symptomatic LSS, addressing all identifiable etiologies may not be required. In formulating a treatment plan, it is important to consider that hypertrophic LF has been reported to contribute to between 50 and $85 \%$ of spinal 
canal narrowing (48). In the case of mild percutaneous lumbar decompression, debulking the hypertrophic LF as a predominant causal factor can provide adequate overall decompression within the central spinal canal, even in cases of multiple other contributing etiologies.

At one-year follow-up, pain intensity for study cohort patients as measured by VAS showed a statistically significant improvement of 2.9 points from baseline to one-year follow-up. A drop of 2 or more points is considered to be a clinically important change $(49,50)$. This level of clinically important improvement was also demonstrated at 12-week and 6-month follow-up intervals, where mean improvement was 2.7 and 2.5 points, respectively. This significant change at 12 weeks, followed by consistency over time, demonstrates the durability of percutaneous lumbar decompression in the reduction of pain (Fig. 2).

Study cohort patients also demonstrated a significant improvement in physical function as measured by both ODI and all ZCQ domains and sub-domains at oneyear follow-up. ODI scores decreased from a mean of 49.4 at baseline to 32.0 at one-year follow-up, an average change of 17.4 points. Published reports of clinically important change in ODI range from 4 to 18.4 points (50-53). Specifically, an ODI validation study by Fritz et al (53) suggests that clinical relevance is established with approximately 6 points of improvement from baseline. It is also of interest that at an FDA panel meeting, a suggestion was made that a minimum 15-point change in ODI was clinically significant (54). As with pain reduction, in addition to the relevant 17.4 point ODI improvement achieved at one year, mean scores for these patients demonstrated a statistically significant improvement at interim 12-week and 6-month visits, with mean improvements of 14.3 and 14.4 points, respectively. Again, this demonstration of statistically significant improvement at 12 weeks, followed by no significant difference between the 12-week, 26-week and one-year postbaseline periods, shows the durability of mild percutaneous decompression in improving physical function (Fig. 3).

The ZCQ Symptom Severity domain score decreased from 3.5 to 2.3 over one year, an improvement of $1.2(34.3 \%)$, and the Physical Function domain score decreased from 2.7 to 1.9, an improvement of 0.8 (29.6\%). Further analysis of the Symptom Severity subdomains show a decrease in the Pain sub-domain from 3.9 at baseline to 2.7 at one year, an improvement of $1.2(30.8 \%)$, and a decrease in the Neuro-Ischemic subdomain from 3.0 to 1.9, an improvement of 1.1 (36.7\%).
Validation studies have reported that ZCQ domain improvements of at least 0.5 indicate a clinically relevant change $(24,36,55)$. Importantly, all ZCQ domains at $12-$ week, six-month and one-year follow-up periods demonstrated improvement greater than 0.5 , showing remarkable stability through one-year follow-up (Fig. 4).

The mean Patient Satisfaction score of 1.86 at oneyear follow-up indicated that patients were satisfied with their overall outcomes after percutaneous lumbar decompression. Also importantly, 30 of 34 patients $(88 \%)$ reported a Patient Satisfaction score of 2.5 or better, indicating that they were satisfied with the mild procedure $(24,36,55)$.

There were no reports of serious complications in this study, which is in line with other published reports of mild lumbar decompression safety results (18$23,25,28,56)$. This can be compared to the safety profile of decompression surgery as reported by the Spine Patient Outcomes Research Trial (SPORT) investigators (57). In the surgical arm of SPORT, $9.9 \%$ of patients experienced complications, including dural tear in $9.2 \%$ of patients. Mean blood loss for SPORT surgical patients was $314 \mathrm{~mL}$, and $9.5 \%$ of SPORT surgical patients required intraoperative blood transfusion. This can be compared to negligible blood loss for patients undergoing percutaneous lumbar decompression in this study, and no blood transfusions.

In addition to enhanced safety and significant improvements in mobility and pain reduction, consideration must also be given to other mild procedure characteristics that provide important patient and cost benefits. Average procedure time in this study was 41 minutes and all patients were discharged on the same day as the procedure. This can be compared to surgical procedure times reported in SPORT of 128 minutes, and an average hospital stay of more than 3 days. Percutaneous lumbar decompression requires only light sedation, as compared to decompression surgery which requires the use of general anesthesia.

The author acknowledges the limitations of this study. There was no control group and the patients were treated at a single center. Although randomization was considered, due to the complexity of randomizing patients to a decompression procedure requiring general anesthesia, a longer hospital stay, potentially higher expenses and greater complication risks, the low likelihood of timely enrollment and the potential ethical considerations caused the concept to be abandoned. The strengths of this study include its prospective design and the use of validated patient outcome 
assessment tools for evaluation of pain intensity and functional disability. Specifically, VAS, ODI and ZCQ have been verified as reproducible, internally consistent, valid, and highly responsive outcome assessment measures of patients with LSS $(24,30,50-53)$.

\section{Conclusion}

In this study, the mild procedure was shown to be safe, with properly diagnosed patients experiencing significant improvement in mobility and significant reduction of pain at one year after the procedure. Oneyear follow-up was not statistically different than interim follow-ups, indicating that improvement following treatment occurred as early as 12 weeks and was main- tained through one year. This high degree of consistency over time indicates the durability of percutaneous lumbar decompression in the treatment of neurogenic claudication in patients with symptomatic LSS.

mild percutaneous lumbar decompression provides an early alternative for LSS patients following failure of conservative therapy, and before more invasive surgical decompression. Percutaneous lumbar decompression offers shorter procedure times, the use of less sedation, and shorter hospital stays. Further, there is less risk of iatrogenic spinal instability versus more invasive surgeries, and this procedure involves no implants.

\section{References}

1. Arnoldi CC, Brodsky AE, Cauchoix J, Crock HV, Dommisse GF, Edgar MA, Gargano FP, Jacobson RE, Kirkaldy-Willis WH, Kurihara A, Langenskiöld A, Macnab I, Mclvor GW, Newman PH, Paine KW, Russin LA, Sheldon J, Tile M, Urist MR, Wilson WE, Wiltse LL. Lumbar spinal stenosis and nerve root entrapment syndromes. Definition and classification. Clin Orthop Relat Res 1976; 115:4-5.

2. Porter RW. Spinal stenosis and neurogenic claudication. Spine (Phila Pa 1976) 1996; 21:2046-2052.

3. Amundsen $\mathrm{T}$, Weber $\mathrm{H}$, Nordal HJ, Magnaes $\mathrm{B}$, Abdelnoor $\mathrm{M}$, Lilleås $\mathrm{F}$. Lumbar spinal stenosis: Conservative or surgical management? Spine (Phila Pa 1976) 2000; 25:1424-1436.

4. Arbit E, Pannullo S. Lumbar stenosis: A clinical review. Clin Orthop Relat Res 2001; 384:137-143.

5. Thomas SA. Spinal stenosis: History and physical examination. Phys Med Rehabil Clin N Am 2003; 14:29-39.

6. Doorly TP, Lambing CL, Malanga GA, Maurer PM, Rashbaum RF. Algorithmic approach to the management of the patient with lumbar spinal stenosis. J Fam Pract 2010; 59(8 Suppl algorithmic):S1-S8.

7. Suri P, Rainville J, Kalichman L, Katz JN. Does this older adult with lower extremity pain have the clinical syndrome of lumbar spinal stenosis? JAMA 2010; 304:2628-2636.

8. Atlas SJ, Delitto A. Spinal stenosis: Surgical versus nonsurgical treatment. Clin Orthop Relat Res 2006; 443:198-207.

9. Katz JN, Harris MB. Lumbar spinal stenosis. N Engl J Med 2008; 358:818-825.

10. Manchikanti L, Cash KA, McManus CD,
Pampati V, Fellows B. Results of 2-year follow-up of a randomized, double-blind, controlled trial of fluoroscopic caudal epidural injections in central spinal stenosis. Pain Physician 2012; 15: 371-384.

11. Manchikanti L, Cash KA, McManus CD Damron KS, Pampati V, Falco FJE. Lumbar interlaminar epidural injections in central spinal stenosis: Preliminary results of a randomized, double-blind, active control trial. Pain Physician 2012; 15:51-63.

12. Manchikanti L, Malla Y, Cash KA, McManus CD, Pampati V. Fluoroscopic epidural injections in cervical spinal stenosis: Preliminary results of a randomized, doubleblind, active control trial. Pain Physician 2012; 15:E59-E70.

13. Manchikanti L, Singh V, Cash KA, Pampati V, Datta S. Management of pain of post lumbar surgery syndrome: One-year results of a randomized, double doubleblind, active controlled trial of fluoroscopic caudal epidural injections. Pain Physician 2010; 13:509-521.

14. Manchikanti L, Pampati V, Boswell MV Smith HS, Hirsch JA. Analysis of the growth of epidural injections and costs in the Medicare population: A comparative evaluation of 1997, 2002, and 2006 data. Pain Physician 2010; 13:199-212.

15. Manchikanti L, Pampati V, Falco FJE, Hirsch JA. Growth of spinal interventional pain management techniques: Analysis of utilization trends and medicare expenditures 2000 to 2008. Spine (Phila Pa 1976) 2012 July 11 [Epub ahead of print].

16. Park $\mathrm{CH}$, Lee $\mathrm{SH}$, Jung JY. Dural sac cross sectional area does not correlate with efficacy of percutaneous adhesiolysis in single level lumbar spinal stenosis. Pain Physician 2011; 14:377-382.
17. Manchikanti L, Pampati V, Cash RT. Protocol for evaluation of the comparative effectiveness of percutaneous adhesiolysis and caudal epidural steroid injections in the low back and/or lower extremity pain without post surgery syndrome or spinal stenosis. Pain Physician 2012; 13: E91-E110.

18. Chopko BW. A novel method for treatment of lumbar spinal stenosis in highrisk surgical candidates: Pilot study experience with percutaneous remodeling of ligamentum flavum and lamina. J Neurosurg Spine 2011; 14:46-50.

19. Deer TR, Mekhail N, Lopez G, Amirdelfan K. Minimally invasive lumbar decompression for spinal stenosis. JNR 2011; 1:29-32.

20. Schomer DF, Solsberg D, Wong W, Chopko BW. mild ${ }^{\circledR}$ lumbar decompression for the treatment of lumbar spinal stenosis. The Neuroradiology Journal 2011; 24:620-626.

21. Basu S. mild ${ }^{\circledR}$ procedure: Single-site prospective IRB study. Clin ] Pain 2012; 28:254-258.

22. Brown LL. A double-blind, randomized, prospective study of epidural steroid injection vs. the mild ${ }^{\circledR}$ procedure in patients with symptomatic lumbar spinal stenosis. Pain Pract 2012; 12:333-341.

23. Mekhail N, Vallejo R, Coleman $\mathrm{MH}, \mathrm{Be}-$ nyamin RM. Long-term results of percutaneous lumbar decompression mild $\mathbb{}$ for spinal stenosis. Pain Practice 2012; 12:184-193.

24. Lingreen R, Grider JS. Retrospective review of patient self-reported improvement and post-procedure findings for mild (minimaly invasive lumar decompression) Pain Physician 2010; 13: 555-560. 
25. Chopko B, Caraway DL. MiDAS I (mild ${ }^{\circledR}$ Decompression Alternative to Open Surgery): A preliminary report of a prospective, multi-center clinical study. Pain Physician 2010; 13:369-378.

26. Briggs VG, Li W, Kaplan MS, Eskander MS, Franklin PD. Injection treatment and back pain associated with degenerative lumbar spinal stenosis in older adults. Pain Physician 2010; 13: E347-E355.

27. Yi $X$, McPherson B. Application of $X$ STOP Device in the treatment of lumbar spinal stenosis. Pain Physician 2010; 13: E327-E336.

28. Deer TR, Kapural L. New image-guided ultra-minimally invasive lumbar decompression method: The mild® procedure. Pain Physician 2010; 13:35-41.

29. Stucki G, Liang MH, Fossel AH, Katz JN. Relative responsiveness of conditionspecific and generic health status measures in degenerative lumbar spinal stenosis. J Clin Epidemiol 1995; 48:1369-1378.

30. Stucki G, Daltroy L, Liang MH, Lipson SJ, Fossel AH, Katz JN. Measurement properties of a self-administered outcome measure in lumbar spinal stenosis. Spine (Phila Pa 1976)1996; 21:796-803.

31. Pratt RK, Fairbank JCT, Virr A. The reliability of the Shuttle Walking Test, the Swiss Spinal Stenosis Questionnaire, the Oxford Spinal Stenosis Score and the Oswestry Disability Index in the assessment of patients with lumbar spinal stenosis. Spine (Phila Pa 1976) 2002; 27:84-91.

32. Amundsen $T$, Weber $H$, Lilleås $F$, Nordal HJ, Abdelnoor M, Magnaes B. Lumbar spinal stenosis. Clinical and radiologic features. Spine (Phila Pa 1976) 1995; 20:1178-1186.

33. Beattie PF, Meyers SP, Stratford P, Millard RW, Hollenberg GM. Associations between patient report of symptoms and anatomic impairment visible on lumbar magnetic resonance imaging. Spine (Phila Pa 1976) 2000; 25:819-828.

34. Haig AJ, Tong HC, Yamakawa KSJ, Parres C, Quint DJ, Chiodo A, Miner JA, Phalke VC, Hoff JT, Geisser ME. Predictors of pain and function in persons with spinal stenosis, low back pain, and no back pain. Spine (Phila Pa 1976) 2006; 31:2950-2957.

35. Siebert E, Prüss $H$, Klingebiel R, Failli $V$, Einhäupl KM, Schwab JM. Lumbar spinal stenosis: syndrome, diagnostics and treatment. Nat Rev Neurol 2009; 5:392403.

36. Hall S, Bartleson JD, Onofrio BM, Baker HL, Okazaki H, O'Duffy JD. Lumbar spinal stenosis. Clinical features, diagnostic procedures, and results of surgical treatment in 68 patients. Ann Intern Med 1985; 103:271-275.

37. Thomé C, Zevgaridis D, Leheta $\mathrm{O}$, Bäzner H, Pöckler-Schöniger C, Wöhrle J, Schmiedek P. Outcome after less-invasive decompression of lumbar spinal stenosis: A randomized comparison of unilateral laminotomy, bilateral laminotomy, and laminectomy. J Neurosurg: Spine 2005; 3:129-141.

38. Çavusoglu H, Kaya RA, Turkmenoglu ON, Tuncer C, Çolak I, Aydin Y. Midterm outcome after unilateral approach for bilateral decompression of lumbar spinal stenosis: 5-Year prospective study. Eur Spine J 2007; 16:2133-2142.

39. Ryu SJ, Kim IS. Interspinous implant with unilateral laminotomy for bilateral decompression of degenerative lumbar spinal stenosis in elderly patients. J Korean Neurosurg Soc 2010; 47:338-344.

40. Verbiest H. A radicular syndrome from developmental narrowing of the lumbar vertebral canal. J Bone Joint Surg $\mathrm{Br}$ 1954; 36:230-237.

41. Rydevik B, Brown MD, Lundborg G. Pathoanatomy and pathophysiology of nerve root compression. Spine (Phila Pa 1976) 1984; 9:7-15.

42. Olmarker K, Rydevik B, Holm S. Edema formation in spinal nerve roots induced by experimental, graded compression. An experimental study on the pig cauda equina with special reference to differences in effects between rapid and slow onset of compression. Spine (Phila $\mathrm{Pa}$ 1976) 1989; 14:569-573.

43. Campbell MJ, Carreon LY, Glassman SD, McGinnis MD, Elmlinger BS. Correlation of spinal canal dimensions to efficacy of epidural steroid injection in spinal stenosis. J Spinal Disord Tech 2007; 20:168-171.

44. Grubb SA, Lipscomb HJ, Coonrad RW. Degenerative adult onset scoliosis. Spine (Phila Pa 1976) 1988; 13:241-245.

45. Simotas AC. Nonoperative treatment for lumbar spinal stenosis. Clin Orthop Relat Res 2001; 384:153-161.

46. Manchikanti L, Helm S, Singh V, Benyamin RM, Datta S, Hayek SM, Fellows B, Boswell MV. An algorithmic approach for clinical management of chronic spinal pain. Pain Physician 2009; 12:E225-E264.

47. Manchikanti L, Cash KA, McManus CD, Damron KS, Pampati V, Falco FJE. Lumbar interlaminar epidural injections in central spinal stenosis: Preliminary results of a randomized, double-blind, active control trial. Pain Physician 2012;
15:51-63.

48. Hansson T, Suzuki N, Hebelka H, Gaulitz A. The narrowing of the lumbar spinal canal during MRI: The effects of the disc and ligamentum flavum. Eur Spine ] 2009; 18:679-686.

49. Todd KH, Funk KG, Funk JP, Bonacci R. Clinical significance of reported changes in pain severity. Ann Emerg Med 1996; 27:485-489.

50. Ostelo RWJG, Deyo RA, Stratford P, Waddell G, Croft P, Von Korff M, Bouter LM, de Vet HC. Interpreting change scores for pain and functional status in low back pain: Towards international consensus regarding minimal important change. Spine (Phila Pa 1976) 2008; 33:90-94.

51. Roland M, Fairbank J. The Roland-Morris Disability Questionnaire and the Oswestry Disability Questionnaire. Spine (Phila Pa 1976) 2000; 25:3115-3124.

52. Mirza SK, Deyo RA. Systematic review of randomized trials comparing lumbar fusion surgery to nonoperative care for treatment of chronic back pain. Spine (Phila Pa 1976) 2007; 32:816-823.

53. Fritz JM, Irrgang JJ. A comparison of a modified Oswestry Low Back Pain Disability Questionnaire and the Quebec Back Pain Disability Scale. Physical Therapy 2001; 81:776-788.

54. FDA, Center for Devices and Radiological Health, Orthopedic and Rehabilitation Devices Panel Meeting, Friday, September 9, 2005. www.fda.gov/ohrms/dockets/ac/05/transcripts/2005-4181t2.htm

55. Zucherman JF, Hsu KY, Hartjen CA, Mehalic TF, Implicito DA, Martin MJ, Johnson DR, Skidmore GA, Vessa PP, Dwyer JW, Puccio S, Cauthen JC, Ozuna RM. A prospective randomized multi-center study for the treatment of lumbar spinal stenosis with the X STOP interspinous implant: 1-year results. Eur Spine J 2004; 13:22-31.

56. Lingreen R, Grider JS. Retrospective review of patient self-reported improvement and post-procedure findings for mild® (minimally invasive lumbar decompression). Pain Physician 2010; 13:555560.

57. Weinstein JN, Tosteson TD, Lurie JD, Tosteson AN, Blood E, Hanscom B, Herkowitz $\mathrm{H}$, Cammisa F, Albert T, Boden SD, Hilibrand A, Goldberg H, Berven S, An H; SPORT Investigators. Surgical versus nonsurgical therapy for lumbar spinal stenosis. N Engl J Med 2008; 358:794810. 